\section{В.К. Сокол}

Харьковский национальный медицинский университет, Харьков, Украина

Надійшла: 12.11.2020

Прийнята: 09.12.2020
DOI: https://doi.org/10.26641/1997-9665.2020.4.72-78

УДК 340.66:617.58-001

ХАРАКТЕРИСТИКА ТЕЛЕСНЫХ ПОВРЕЖДЕНИЙ ПРИ АВТОМОБИЛЬНОЙ ТРАВМЕ ТАЗОВОГО ПОЯСА И НИЖНИХ КОНЕЧНОСТЕЙ

Sokol V.K. (D) $\square$ Characteristics of bodily injuries of the pelvic girdle and lower extremities in car trauma. Kharkiv National Medical University, Kharkiv, Ukraine.

ABSTRACT. Background. Fractures of the pelvic girdle and lower extremities as a result of a road traffic accident are the most frequent localization of injuries in victims, however, the structure of pedestrian and intra-salon injuries has not been sufficiently studied. Objective - to study the nature of injuries in victims of a car injury to the pelvic girdle and lower extremities. Methods. Research material - 170 acts of primary forensic medical examinations of victims with fractures of the pelvic bones and long bones of the lower extremities, received as a result of a non-lethal automobile injury. An expert assessment of the nature of bodily injuries was carried out at the Kharkiv Regional Bureau of Forensic Medicine (KRBSFM) within a period of no more than 1 month after injury. Acts of primary forensic medical examinations were selected at random for the period February - June 2018. Research methods - retrospective analysis, descriptive statistics. Results. Among the injured as a result of a car injury - $129(75.9 \%)$ pedestrians, $23(13.5 \%)$ drivers, $14(8.2 \%)$ front seat passengers and $4(2.4 \%)$ rear seat passengers. Thus, pedestrians and car drivers are the most vulnerable to road traffic injuries; the most protected rear seat passengers. Men predominated among the drivers; in the remaining groups of victims, the gender distribution was generally even. Among the participants in the accident were mainly people of working age. Injuries to the chest $(26.5 \%)$, head $(25.9 \%)$, abdomen (16.5\%) prevailed among the associated injuries. Conclusion. A distinctive feature of injuries sustained as a result of a collision of a pedestrian or a car with another car with a relatively low speed of movement was an isolated injury to the bones of the pelvic girdle or lower extremities, both during pedestrian and intra-salon trauma. All the victims had injuries of the integumentary system of various localization in the form of subcutaneous hematomas and abrasions $(158 ; 92.9 \%)$, bruised lacerations $(96 ; 56.5 \%)$, stamp injuries $(62 ; 36.5 \%)$. The main mechanism of pedestrian injury is the direct impact of the traumatic force with the formation of primary injuries in the form of bumper fractures of the shin bones (35.9\%), hip (22.4\%) and pelvis $(10 \%)$.

Key words: road traffic injury, pelvic fractures, fractures of the lower extremities, forensic medical examination.

\title{
Citation:
}

Sokol VK. [Characteristics of bodily injuries of the pelvic girdle and lower extremities in car trauma]. Morphologia. 2020;14(4):72-8. Russian.

DOI: https://doi.org/10.26641/1997-9665.2020.4.72-78

Sokol V.K. 0000-0002-8892-1765

\sokol_vk@ukr.net

(c) SI «Dnipropetrovsk Medical Academy of the Ministry of Health of Ukraine», «Morphologia»

\section{Введение}

Переломы тазового пояса и нижних конечностей в результате механической травмы являются одним из наиболее распространенных повреждений опорно-двигательной системы. Переломы таза составляют 2-8\% всех повреждений скелета [1]. Переломы бедренной кости, согласно сводным статистическим данным Всемирной организации здравоохранения (ВО3), Всемирного банка и бюро по изучению глобального бремени болезней (Global Burden of Disease (GBD)), ежегодно регистрируются у 1 млн - 2,9 млн пострадавших [2]. Частота переломов диафиза большеберцовой кости достигает 16,9 на 100000 населения в год [3].

Одним из наиболее частых механизмов образования переломов тазового пояса и нижних конечностей является воздействие высокоэнергетической травмы в результате дорожнотранспортных происшествий (ДТП). Такие повреждения часто сочетаются с переломами других сегментов опорно-двигательной системы (множественная травма) и/или с повреждениями других органов и систем организма человека (сочетанная травма). Лечение пациентов данной категории нередко включает пролонгированный 
госпитальный период, сопровождается длительным пребыванием на больничном листе с нередкой инвалидизацией пострадавших трудоспособного возраста и, как следствие, приводит к значительным экономическим затратам общества $[4$, 5]. Политравма, сопутствующая ДТП, нередко приводит к летальным исходам: дорожнотранспортная травма занимает 8 место среди причин смерти в общей популяции и 1 место - у детей и молодых людей в возрасте 5 - 29 лет [6]. Социально-экономические потери общества вследствие летальных ДТП превышают аналогичные показатели при злокачественных заболеваниях, болезнях сердца и цереброваскулярных заболеваниях [7].

Эпидемиология и структура политравмы при летальных ДТП изучаются всесторонне как на национальных уровнях, так и ВОЗ. В то же время характеристика повреждений при нелетальной дорожно-транспортной травме освещена менее подробно. Недостаточно изучена частота и характеристика повреждений нижних конечностей и тазового пояса при ДТП, хотя общеизвестно, что именно эти сегменты опорнодвигательной системы наиболее уязвимы как у пешеходов при первичном контакте с транспортным средством, так и у водителей и пассажиров при внутрисалонной травме [8-10].

Цель - изучить характер телесных повреждений у пострадавших в результате автомобильной травмы тазового пояса и нижних конечностей.

\section{Материалы и методы}

Материал исследования - 170 актов первичных судебно-медицинских экспертиз пострадавших с переломами костей таза, и/или бедренной кости, и/или костей голени, полученных в результате нелетальной автомобильной травмы. Во всех случаях экспертная оценка характера травматических повреждений производилась в Харьковском областном бюро судебно-медицинской экспертизы (ХОБСМЭ) в срок не более 1 мес. после травмы. Акты первичных судебномедицинских экспертиз отбирались случайной выборкой за период февраль - июнь 2018 года.

Критерии включения - изолированные переломы костей таза, бедренной кости или костей голени; нелетальная политравма с переломами костей таза, длинных костей нижних конечностей в качестве ведущей травмы, полученная при автомобильной травме.

Критерии исключения - нелетальная политравма, в которой переломы костей таза и нижних конечностей являлись сопутствующей травмой; автотравма, при которой судебно-медицинская экспертиза проводилась в сроки, превышающие 1 мес.; переломы таза и нижних конечностей, полученные в результате других механизмов (кроме автотравмы), летальная автотравма.

При изучении структуры автомобильной травмы учитывались следующие сопутствующие повреждения: сотрясения головного мозга легкой и средней степени, непроникающие закрытые переломы ребер, непроникающая закрытая травма живота, ушибы головы, грудной клетки, повреждения покровной системы.

Bce 170 пострадавших в результате автотравмы были разделены на группы: 1 - пешеходы $(\mathrm{n}=129 ; 75,9 \%) ; 2$ - водители $(\mathrm{n}=23 ; 13,5 \%) ; 3$ пассажиры переднего сиденья $(\mathrm{n}=14 ; 8,2 \%) ; 4$ пассажиры заднего сиденья $(\mathrm{n}=4 ; 2,4 \%)$.

Методы исследования - ретроспективный анализ, описательная статистика.

Результаты и их обсуждение

Средний возраст пострадавших при автотравме составил 46,8 $\pm 24,7$ года (10 - 81 год); наблюдалось незначительное преобладание мужчин $(52,4 \%)$. Основной контингент пострадавших составили пешеходы и водители легковых автомобилей в возрастной группе 31 - 50 лет (36,5\% и 6,5\% соответственно), и практически треть $(30,0 \%)$ пешеходов были старше 51 года. Интересно отметить, что в общей группе пострадавших соотношение количество мужчин:количество женщин составило $1,1: 1$; в группе водителей легковых автомобилей - 2,8:1; в группе пешеходов - 0,95:1 (табл. 1).

Отличительной особенностью автомобильной травмы на нашем материале явилась относительно небольшая скорость транспортного средства в момент ДТП, не превышавшая 30 - 40 км/ч. Преобладали ДТП в городе $(157 ; 92,4 \%)$; наезд на пешехода в сельских населенных пунктах происходил в 5,3\% случаев, столкновение движущихся ТС на трассах - в 2,3\% случаев.

Учитывая тот факт, что у всех 170 пострадавших имело место повреждение покровной системы либо при первичном контакте с автомобилем, либо и при вторичной травме при забрасывании пешехода на капот с последующим падением на землю, все переломы таза и нижних конечностей рассматривались как сочетанные. Среди повреждений кожных покровов различной локализации преобладали подкожные гематомы и ссадины $(158 ; 92,9 \%)$, ушиблено-рваные раны (96; 56,5\%), штамп-повреждения (отпечатки деталей бампера, капота, салона автомобиля) - 62; $36,5 \%$.

Как видно из таблицы 2, чаще всего в ДТП травмировались голень $(52,4 \%)$, бедро $(28,2 \%)$, грудная клетка $(26,5 \%)$, голова $(25,9 \%)$, живот $(16,5 \%)$ и таз $(11,8 \%)$. Наиболее уязвимыми участниками ДТП представляются водитель и пассажир переднего сиденья легкового автомобиля: в среднем на долю каждого из них приходится соответственно по 3 и 1,9 повреждения различной локализации и различной степени тяжести. У каждого пешехода в среднем образовалось по 1,7 повреждения (табл. 2). 
Распределение по полу и возрасту пострадавших при автомобильной травме

\begin{tabular}{|c|c|c|c|c|c|}
\hline & $\begin{array}{c}1 \\
\mathrm{n}=129 ; 75,9 \%\end{array}$ & $\begin{array}{c}2 \\
\mathrm{n}=23 ; 13,5 \%\end{array}$ & $\begin{array}{c}3 \\
\mathrm{n}=14 ; 8,2 \%\end{array}$ & $\begin{array}{c}4 \\
\mathrm{n}=4 ; 2,4 \%\end{array}$ & $\begin{array}{c}\text { Всего } \\
\mathrm{n}=170 ; 100 \%\end{array}$ \\
\hline \multicolumn{6}{|l|}{ Пол } \\
\hline - мужской & $63 ; 37,1 \%$ & $17 ; 10,0 \%$ & $9 ; 5,3 \%$ & - & $89 ; 52,4 \%$ \\
\hline - женский & $66 ; 38,8 \%$ & $6 ; 3,5 \%$ & $5 ; 2,9 \%$ & $4 ; 2,4 \%$ & $81 ; 47,6 \%$ \\
\hline \multicolumn{6}{|c|}{ Возраст, лет } \\
\hline $10-20$ & $4 ; 2,4 \%$ & - & - & $1 ; 0,6 \%$ & $5 ; 2,9 \%$ \\
\hline $21-30$ & $12 ; 7,1 \%$ & $3 ; 1,8 \%$ & $2 ; 1,2 \%$ & $3 ; 1,8 \%$ & $20 ; 11,8 \%$ \\
\hline $31-40$ & $26 ; 15,3 \%$ & $8 ; 4,7 \%$ & $4 ; 2,4 \%$ & - & $38 ; 22,4 \%$ \\
\hline $41-50$ & $36 ; 21,2 \%$ & $7 ; 4,1 \%$ & $7 ; 4,1 \%$ & - & $50 ; 29,4 \%$ \\
\hline $51-60$ & $38 ; 22,4 \%$ & $5 ; 2,9 \%$ & $1 ; 0,6 \%$ & - & $44 ; 25,9 \%$ \\
\hline$<61$ & $13 ; 7,6 \%$ & - & - & - & $13 ; 7,6 \%$ \\
\hline
\end{tabular}

Примечание: 1 - пешеходы; 2 - водители, 3 - пассажиры переднего сиденья, 4 - пассажиры заднего сиденья легкового автомобиля.

Таблица 2

Структура повреждений различных областей тела у потерпевших при автомобильной травме

\begin{tabular}{|c|c|c|c|c|c|}
\hline Признак & $\begin{array}{c}1 \\
(\mathrm{n}=129)\end{array}$ & $\begin{array}{c}2 \\
(n=23)\end{array}$ & $\begin{array}{c}3 \\
(n=14)\end{array}$ & $\begin{array}{c}4 \\
(n=4)\end{array}$ & $\begin{array}{c}\text { Всего больных } \\
(\mathrm{n}=170)\end{array}$ \\
\hline Голова & $20 ; 11,8 \%$ & $18 ; 10,6 \%$ & $5 ; 2,9 \%$ & $1 ; 0,6 \%$ & $44 ; 25,9 \%$ \\
\hline Шея & $3 ; 1,8 \%$ & $7 ; 4,1 \%$ & $4 ; 2,4 \%$ & - & $14 ; 8,2 \%$ \\
\hline Плечо & $8 ; 4,7 \%$ & - & $3 ; 1,8 \%$ & - & $11 ; 6,5 \%$ \\
\hline Предплечье & $4 ; 2,4 \%$ & $1 ; 0,6 \%$ & - & - & $5 ; 2,9 \%$ \\
\hline Кисть & $6 ; 3,5 \%$ & $2 ; 1,2 \%$ & - & - & $8 ; 4,7 \%$ \\
\hline Грудная клетка & $28 ; 16,5 \%$ & $16 ; 9,4 \%$ & $1 ; 0,6 \%$ & - & $45 ; 26,5 \%$ \\
\hline Живот & $19 ; 11,2 \%$ & $8 ; 4,7 \%$ & $1 ; 0,6 \%$ & - & $28 ; 16,5 \%$ \\
\hline Таз & $17 ; 10,0 \%$ & $3 ; 1,8 \%$ & - & - & $20 ; 11,8 \%$ \\
\hline Бедро & $37 ; 21,8 \%$ & $4 ; 2,4 \%$ & $5 ; 2,9 \%$ & $2 ; 1,2 \%$ & $48 ; 28,2 \%$ \\
\hline Голень & $72 ; 42,4 \%$ & $8 ; 4,7 \%$ & $7 ; 4,1 \%$ & $2 ; 1,2 \%$ & $89 ; 52,4 \%$ \\
\hline Стопа & $6 ; 3,5 \%$ & $1 ; 0,6 \%$ & $1 ; 0,6 \%$ & - & $8 ; 4,7 \%$ \\
\hline Всего травм & $220 ; 129,4 \%$ & $68 ; 40,0 \%$ & $27 ; 15,9 \%$ & $5 ; 2,9 \%$ & $320 ; 100 \%$ \\
\hline
\end{tabular}

Примечание: 1 - пешеходы; 2 - водители, 3 - пассажиры переднего сиденья, 4 - пассажиры заднего сиденья легкового автомобиля.

При исследовании структуры повреждений костей таза и нижних конечностей установлено, что в среднем на 1 пострадавшего, независимо от вида дорожно-транспортной травмы, приходится в среднем 1,1 перелома данной локализации. Переломы костей таза встречались преимущественно у пешеходов и, судя по характеру смещения фрагментов, образовались в результате первичной травмы по типу бамперных переломов. Такой же механизм переломов является преобладающим при переломах длинных костей нижних конечностей у пешеходов. Среди переломов этой локализации преобладали диафизарные переломы бедра $(28,8 \%)$ и голени $(40,6 \%)$ - табл. 3 . 
Таблица 3

Структура переломов костей таза и длинных костей нижних конечностей в различных группах пострадавших в автомобильной травме

\begin{tabular}{|c|c|c|c|c|c|}
\hline $\begin{array}{c}\text { Характер травмы нижних конечностей / } \\
\text { Группы пострадавших }\end{array}$ & $\begin{array}{c}1 \\
(\mathrm{n}=129)\end{array}$ & $\begin{array}{c}2 \\
(\mathrm{n}=23)\end{array}$ & $\begin{array}{c}3 \\
(n=14)\end{array}$ & $\begin{array}{c}4 \\
(n=4)\end{array}$ & $\begin{array}{c}\text { Всего боль- } \\
\text { ных } \\
(n=170)\end{array}$ \\
\hline Разрыв лонного сочленения & $3 ; 1,8 \%$ & - & - & - & $3 ; 1,8 \%$ \\
\hline Перелом доной кости & $6 ; 3,5 \%$ & - & - & - & $6 ; 3,5 \%$ \\
\hline Перелом седалищной кости & $5 ; 2,9 \%$ & - & - & - & $5 ; 2,9 \%$ \\
\hline Перелом крыла таза & $3 ; 1,8 \%$ & - & - & - & $3 ; 1,8 \%$ \\
\hline $\begin{array}{l}\text { Перелом вертлужной впадины с цен- } \\
\text { тральным вывихом бедра }\end{array}$ & - & $3 ; 1,8 \%$ & - & - & $3 ; 1,8 \%$ \\
\hline $\begin{array}{l}\text { Перелом проксимального отдела бед- } \\
\text { ренной кости }\end{array}$ & $5 ; 2,9 \%$ & $1 ; 0,7 \%$ & - & - & $6 ; 3,5 \%$ \\
\hline Перелом диафиза бедренной кости & $38 ; 22,4 \%$ & $4 ; 2,4 \%$ & $4 ; 2,9 \%$ & $3 ; 1,8 \%$ & $49 ; 28,8 \%$ \\
\hline $\begin{array}{l}\text { Перелом дистального отдела бедренной } \\
\text { кости }\end{array}$ & $4 ; 2,4 \%$ & $4 ; 2,4 \%$ & $1 ; 0,7 \%$ & - & $9 ; 5,3 \%$ \\
\hline $\begin{array}{l}\text { Перелом проксимального отдела боль- } \\
\text { шеберцовой кости }\end{array}$ & $11 ; 6,5 \%$ & $6 ; 3,5 \%$ & $2 ; 1,2 \%$ & - & $19 ; 11,2 \%$ \\
\hline Перелом диафиза костей голени & $61 ; 35,9 \%$ & $4 ; 2,4 \%$ & $3 ; 1,8 \%$ & $1 ; 0,7 \%$ & $69 ; 40,6 \%$ \\
\hline $\begin{array}{l}\text { Перелом дистального отдела костей го- } \\
\text { лени }\end{array}$ & $8 ; 4,7 \%$ & $5 ; 2,9 \%$ & $4 ; 2,4 \%$ & $1 ; 0,7 \%$ & $18 ; 10,6 \%$ \\
\hline Всего переломов & $144 ; 84,7 \%$ & $27 ; 15,9 \%$ & $14 ; 8,2 \%$ & $5 ; 2,9 \%$ & $190 ; 100 \%$ \\
\hline
\end{tabular}

Примечание: 1 - пешеходы; 2 - водители, 3 - пассажиры переднего сиденья, 4 - пассажиры заднего сиденья легкового автомобиля.

Данный характер повреждений соответствует механизму автомобильной травмы, в которой преобладали переднее $(72 ; 42,4 \%)$ и переднебоковое $(63 ; 37,1 \%)$ столкновение движущегося автомобиля с пешеходом. В результате наезда происходит соударение фронтальных частей автомобиля с нижними конечностями пешехода с формированием бамперных переломов костей голени, бедра или таза (локализация бамперного перелома зависит от конструктивных особенностей автомобиля и роста пешехода). Вследствие ударного воздействия ниже уровня центра массы человека возникает вращающий момент, в результате которого голова, верхние конечности и верхняя половина туловища пешехода отклоняются в сторону автомобиля, а таз и нижние конечности смещаются вверх и по ходу движения транспортного средства. В эту фазу обычно происходит второй удар капотом автомобиля в область бедер пешехода $[11,12]$. Изолированное повреждение костей таза у пешеходов в нашем исследовании объясняется относительно невысоким уровнем повреждающей кинетической энергии, которая продуцировалась при резкой остановке движущегося с относительно небольшой скоростью автомобиля. При большей величине травмирующей силы возможно ипсилатеральное повреждение всего полукольца таза или контралатеральное распространение повреждения костной ткани с образованием нестабильного перелома тазового кольца $[13,14]$.

Изолированные переломы бедренной кости или костей голени при ДТП встречаются редко и образуются при столкновении легковых автомобилей между собой или с пешеходом с невысокой (30 - 40 км/ч) скоростью. При увеличении скорости транспортных средств, участвующих в ДТП, соответственно возрастает тяжесть травмы и количество переломов костей скелета. При нелетальной политравме чаще других регистрируются, наряду с переломами таза и нижних конечностей, также и переломы верхних конечностей [15-17]. Для водителей и пассажиров автомобилей более характерны закрытые переломы длинных костей нижних конечностей [15].

Перелом дна вертлужной впадины с центральным вывихом бедра - типичное повреждение водителя легкового автомобиля при фронтальном столкновении [18]; на нашем материале встретилось в $3(1,8 \%)$ наблюдениях. Помимо 
этого, достаточно часто при внутрисалонной травме образовались диафизарные переломы бедра и голени, а также переломы области коленного сустава (дистальный отдел бедренной кости и проксимальный отдел большеберцовой кости) (табл. 3) - характерные повреждения для этого вида автомобильной травмы [19, 20$].$

\section{Заключение}

Отличительной особенностью телесных повреждений, полученных в результате столкновения пешехода или легкового автомобиля с другим легковым автомобилем с относительно невысокой скоростью движения явилось изолированное повреждение костей тазового пояса или нижних конечностей как при пешеходной, так и при внутрисалонной травме. У всех потерпевших отмечались травмы покровной системы различной локализации в виде подкожных гематом и ссадин (158; 92,9\%), ушиблено-рваных ран (96; $56,5 \%)$, штамп-повреждений $(62 ; 36,5 \%)$. Основной механизм пешеходной травмы - прямое воз- действие травмирующей силы с образованием первичных повреждений в виде бамперных переломов костей голени $(35,9 \%)$, бедра $(22,4 \%)$ и таза $(10 \%)$.

\section{Перспективы дальнейших разработок}

Перспективным представляется изучить структуру переломов тазового кольца и нижних конечностей при пешеходной и внутрисалонной травме, полученной при скорости легкового автомобиля, превышающей 50-60 км/ч.

\section{Конфликт интересов}

Потенциальных или явных конфликтов интересов, связанных с этой рукописью, на момент публикации не существует и не предвидится.

\section{Источники финансирования}

Работа выполнена в рамках научноисследовательской темы «Судово-медичне обгрунтування морфо-клінічніх крітеріїв для експертної оцінки тілесніх ушкоджень, визначення терміну давності та причини смерті» (номер государственной регистрации 0115U000229).

\section{Литературные источники References}

1. Freitas CD, Garotti JER, Nieto J, Guimarfes RP, Ono NK, Honda E, Polesello GC. There have been changes in the incidence and epidemiology of pelvic ring fractures in recent decades? Review Article. Rev Brasil Ortop. 2013;48(6):475-81.

https://doi.org/10.1016/j.rboe.2013.12.013

2. Agarwal-Harding KJ, Meara JG, Greenberg SLM, Hagander L, Zurakowski D, Dyer G. Estimating the Global Incidence of Femoral Fracture from Road Traffic Collisions: A Literature Review. J Bone Joint Surg 2015;97(6):e31 DOI: 10.2106/JBJS.N.00314 PMID: 25788312

3. Larsen P, Elsoe R, Hansen SH, GravenNielsen T, Laessoe U, Rasmussen S. Incidence and epidemiology of tibial shaft fractures. Injury. 2015;46(4):746-50. 10.1016/j.injury.2014.12.027. PMID: 25636535.

4. Pley C, Purohit K, Krkovic M, Abdulkarim A. A health economic analysis of the management of open lower limb fractures in the elderly. Europ J Orthop Surg Traumat. 2020;30:1383-91. https://doi.org/10.1007/s00590-020-02713-3

5. Pan R-H, Chang N-T, Chu D, Hsu K-F, Hsu Y-N, Hsu J-C, Tseng L-Y et al. Epidemiology of Orthopedic Fractures and Other Injuries among Inpatients Admitted due to Traffic Accidents: A 10Year Nationwide Survey in Taiwan. Scie World J 2014; ID 637872: 7 https://doi.org/10.1155/2014/637872

6. Global status report on road safety 2018 . Geneva: World Health Organization; 2018. Licence: CC BY- NC-SA 3.0 IGO. 403 p.

7. Stinner DJ, Edwards D. Surgical
Management of Musculoskeletal Trauma. Surg Clin N Am. 2017;97:1119-31 http://dx.doi.org/10.1016/j.suc.2017.06.005

8. Azami-Aghdash S, Aghaei MH, SadeghiBazarghani H. Epidemiology of Road Traffic Injuries among Elderly People; A Systematic Review and Meta-Analysis. Bull Emerg Trauma. 2018;6(4):279-91. doi: 10.29252/beat-060403. PMID: 30402515

9. Eid HO, Barss P, Adam SH, Torab FC, Lunsjo K, Grivna M, Abu-Zidan FM. Factors affecting anatomical region of injury, severity, and mortality for road trauma in a high-income developing country: lessons for prevention. Injury. 2009;40(7):703-7.

10.1016/j.injury.2008.07.012. PMID: 19117565.

10. Glinsky S.V. [Forensic medical assessment of a car collision in cases of non-fatal injury]. The court-medical expert was elected. Khabarovsk. 2019;18:61-3. Russian.

11. Barkanov VB, Ermilov VV, Civic VV, Vlasova EV, Kinash AA, Podchaynov PV. [Specific injuries of a pedestrian with auto-trauma (bumperfracture)]. Vestnik VolgGMU. 2018;1(65):53-5. Russian. DOI 10.19163/1994-9480-2018-1(65)-5355

12. Leonov SV, Pinchuk PV. [The forensicmedical characteristic of the injuries inflicted to a pedestrian in a road traffic accident by the vehicle in the side and front impact position]. Forensic-med exam. 2016;4:21-4. Russian. doi: 10.17116/sudmed201659421-24

13. Carson JT, Shah SG, Ortega G, Thamyongkit S, Hasenboehler EA, Shafiq B. 
Complications of pelvic and acetabular fractures in 1331 morbidly obese patients $(\mathrm{BMI} \geq 40)$ : a retrospective observational study from the National Trauma Data Bank. Patient Saf Surg. 2018;12:26 doi: 10.1186/s13037-018-0172-2 PMID: 30181776

14. Siada SS, Davis JW, Kaups KL, Dirks RC, Grannis KA. Current outcomes of blunt open pelvic fractures: how modern advances in trauma care may decrease mortality. Trauma Surg Acute Care Open. 2017;2(1):e000136. doi: 10.1136/tsaco-2017000136. eCollection 2017.

15. Sinha AP: Study of Orthopedic Injuries Pattern by Road Traffic Accident Victims. Int J Life Sci Scienti Res. 2017; 3(2): 961-3. DOI:10.21276/ijlssr.2017.3.2.14 PMID: 29766121

16. Guryev SO, Evdoshenko VP, Satsyk SP. [Clinical and nosological structure of injuries of long bones in the victims of road accidents]. Trauma. 2015;16(1):60-3. Ukrainian.
17. Ravikanth R, Varghese PS. Pattern and Distribution of Long Bone Fractures in Victims of Road Traffic Accidents in Bangalore City. Indian J Forensic Med \& Toxicology. 2017;11(1):229-32. DOI: $10.5958 / 0973-9130.2017 .00047 .0$

18. Parkinson F, Kent S, Aldous C, Oosthuizen $\mathrm{G}$, Clarke DL. Patterns of injury seen in road crash victims in a South African trauma centre. S Afr J Surg 2013;51(4):131-4. DOI:10.7196/SAJS.1627 PMID: 24209697

19. Nesterov AV. [The state of the issue of injury inside the car in an accident]. Selected issues of forensic medical examination. Khabarovsk. 2007;82:10-22. Russian.

20. Mayakova MV, Tenkov AA, Kochkarov VI. [Forensic medical assessment of injuries sustained in the passenger compartment by living persons]. Scientific statements. Series Medicine, Pharmacy. 2010;22(93):86-94. Russian.

\section{Сокол В.К. Характеристика тілесних ушкоджень у разі автомобільної травми тазового пояса i нижніх кінцівок.}

РЕФЕРАТ. Актуальність. Переломи тазового пояса і нижніх кінцівок в результаті дорожньотранспортної пригоди - найбільш часта локалізація травм постраждалих, проте структура пішохідної та внутрішньосалонної травми досліджена недостатньо. Мета - вивчити характер тілесних ушкоджень у потерпілих в результаті автомобільної травми тазового пояса і нижніх кінцівок. Методи. Матеріал дослідження - 170 актів первинних судово-медичних експертиз потерпілих з переломами кісток тазу і довгих кісток нижніх кінцівок, отриманих в результаті нелетальної автомобільної травми. Експертна оцінка характеру тілесних ушкоджень проводилася в Харківському обласному бюро судово-медичної експертизи (ХОБСМЕ) в термін не більше 1 міс. після травми. Акти первинних судово-медичних експертиз відбиралися випадковою вибіркою за період лютий - червень 2018 року. Методи дослідження - ретроспективний аналіз, описова статистика. Результати. Серед постраждалих в результаті автомобільної травми - 129 (75,9\%) пішоходів, 23 (13,5\%) водія, 14 (8,2\%) пасажирів переднього сидіння і 4 (2,4\%) пасажира заднього сидіння. Таким чином, найбільш вразливі під час дорожньо-транспортної травми пішоходи і водії легкових автомобілів; найбільш захищені пасажири заднього сидіння. Серед водіїв переважали чоловіки; в інших групах потерпілих гендерний розподіл було в загальному рівномірним. Серед учасників ДТП були переважно особи працездатного віку. Серед поєднаних ушкоджень превалювали травми грудної клітини $(26,5 \%)$, голови $(25,9 \%)$, живота $(16,5 \%)$ Заключенне. Відмінною особливістю тілесних ушкоджень, отриманих в результаті зіткнення пішохода або легкового автомобіля з іншим легковим автомобілем з відносно невисокою швидкістю руху стало ізольоване пошкодження кісток тазового пояса або нижніх кінцівок як при пішохідній, так і при внутрішньосалонній травмі. У всіх потерпілих відзначалися травми покривної системи різної локалізації у вигляді підшкірних гематом і саден (158; $92,9 \%)$, забита-рваних ран $(96 ; 56,5 \%)$, штамп-пошкоджень $(62 ; 36,5 \%)$. Основний механізм пішохідної травми - прямий вплив травмуючої сили з утворенням первинних ушкоджень у вигляді бамперних переломів кісток гомілки $(35,9 \%)$, стегна $(22,4 \%)$ і тазу $(10 \%)$.

Ключові слова: дорожньо-транспортна травма, переломи тазу, переломи нижніх кінцівок, судовомедична експертиза.

Сокол В.К. Характеристика телесных повреждений при автомобильной травме тазового пояса и нижних конечностей.

РЕФЕРАТ. Актуальность. Переломы тазового пояса и нижних конечностей в результате дорожнотранспортного происшествия - наиболее частая локализация травм пострадавших, однако структура пешеходной и внутрисалонной травмы исследована недостаточно. Цель - изучить характер телесных повреждений у пострадавших в результате автомобильной травмы тазового пояса и нижних конечностей. Методы. Материал исследования - 170 актов первичных судебно-медицинских экспертиз потерпевших с переломами костей таза и длинных костей нижних конечностей, полученных в результате нелетальной автомобильной травмы. Экспертная оценка характера телесных повреждений производилась в Харьков- 
ском областном бюро судебно-медицинской экспертизы (ХОБСМЭ) в срок не более 1 мес. после травмы. Акты первичных судебно-медицинских экспертиз отбирались случайной выборкой за период февраль июнь 2018 года. Методы - ретроспективный анализ, описательная статистика. Результаты. Среди пострадавших в результате автомобильной травмы - 129 (75,9\%) пешеходов, 23 (13,5\%) водителя, 14 (8,2\%) пассажиров переднего сиденья и 4 (2,4\%) пассажира заднего сиденья. Таким образом, наиболее уязвимы при дорожно-транспортной травме пешеходы и водители легковых автомобилей; наиболее защищены пассажиры заднего сиденья. Среди водителей преобладали мужчины; в остальных группах потерпевших гендерное распределение было в общем равномерным. Среди участников ДТП были преимущественно лица трудоспособного возраста. Среди сочетанных повреждений превалировали травмы грудной клетки $(26,5 \%)$, головы $(25,9 \%)$, живота $(16,5 \%)$. Заключение. Отличительной особенностью телесных повреждений, полученных в результате столкновения пешехода или легкового автомобиля с другим легковым автомобилем с относительно невысокой скоростью движения явилось изолированное повреждение костей тазового пояса или нижних конечностей как при пешеходной, так и при внутрисалонной травме. У всех потерпевших отмечались травмы покровной системы различной локализации в виде подкожных гематом и ссадин $(158 ; 92,9 \%)$, ушиблено-рваных ран $(96 ; 56,5 \%)$, штамп-повреждений $(62 ; 36,5 \%)$. Основной механизм пешеходной травмы - прямое воздействие травмирующей силы с образованием первичных повреждений в виде бамперных переломов костей голени $(35,9 \%)$, бедра $(22,4 \%)$ и таза $(10 \%)$.

Ключевые слова: дорожно-транспортная травма, переломы таза, переломы нижних конечностей, судебно-медицинская экспертиза. 